Andrzej CZERWIŃSKI ${ }^{*}$, Jan ŁUCZKO*

\title{
VIBRATIONS OF STEEL PIPES AND FLEXIBLE HOSES INDUCED BY PERIODICALLY VARIABLE FLUID FLOW
}

\begin{abstract}
SUMMARY
This paper is concerned with the analysis of a model describing the vibrations of simply supported straight pipes conveying periodically pulsating fluid. The vibrations of the hydraulic system are described by a fourth-order partial differential equation, with the inclusion of geometrical non-linearities. Through the application of the Galerkin method, the non-linear problem is reduced to the solution of four ordinary differential equations. The influence of several significant parameters of the model on the rms value of velocity is investigated. The possibility of exciting sub-harmonic and chaotic excitations at certain intervals of excitation frequency and flow velocity is presented.
\end{abstract}

Keywords: flow-induced vibration, pipeline, critical flow velocity, parametric resonance, chaotic vibrations

\section{DRGANIA SZTYWNYCH I ELASTYCZNYCH PRZEWODÓW WZBUDZONYCH OKRESOWO ZMIENNYM PRZEPEYWEM CIECZY}

$W$ pracy poddano analizie model opisujacy drgania przegubowo podpartych prostoliniowych przewodów, spowodowane pulsacjami prędkości przepływającej cieczy. Ruch układu opisano równaniem różniczkowym czastkowym czwartego rzędu, uwzględniajacym nieliniowości geometryczne. Wykorzystując metodę Galerkina, zagadnienie rozwiqzania równania różniczkowego czqstkowego sprowadzono do problemu analizy układu czterech równań różniczkowych zwyczajnych. Zbadano wpływ wybranych parametrów na wartość skuteczna prędkości drgań. Wykazano możliwość wzbudzania się w pewnych zakresach prędkośsi przeptywu i częstości wymuszenia drgań podharmonicznych i chaotycznych.

Slowa kluczowe: drgania wzbudzone przeptywem, rurociagi, krytyczna prędkość przepływu, rezonans parametryczny, drgania chaotyczne

\section{INTRODUCTION}

Vibrations of pipes conveying fluid is an important problem present in installations which are used in petroleum industry, hydropower systems, chemical plants and hydraulic power systems. A flowing with speed higher than critical may cause the loss of stability of pipe by divergence. A periodically fluctuating flow with speed less than critical may cause the pipes to undergo another type of dynamic instability due to parametric resonance (Bagchi et al. 2009; Jin and Song 2005; Panda and Karr 2008; Zhang et al. 2003).

The problem of modelling pipes conveying fluid and analysing the obtained equations was subject of many research articles. Comprehensive review on various pipe modelling and analysis methods is given in a book (Païdoussis 1998) by Païdoussis. The numerical solutions to the equations is achieved through the use of several analytical methods. Lee and Chung (2002) discuss a case of the pipe fixed at both ends, which is modelled by using the Euler-Bernoulli beam theory. Differential equations obtained by the nonlinear Lagrange strain theory are solved using the Galerkin method. In paper (Gorman et al. 2000) by Gorman et al. the equations of motion of pipe conveying fluid are derived from the continuity and momentum equations. Differential equations are solved by using a combination of the finite difference method and the method of characteristics. In paper (Lee and Park 2006) equations obtained by utilizing the Hamilton's principle are analysed by spectral element method. In turn, Panda and Kar (2008) researched parametric resonance of the pinned-pinned pipe by the method of multiple scales.

This paper is concerned with qualitative analysis of a model describing the vibrations of a pinned-pinned pipe conveying fluid. Motion of the system is described by a non-linear partial differential equation with periodically variable coefficients. The simplifying assumptions are adopted similarly as in the papers (Jin and Song 2005, Païdoussis 1987, 1998; Panda and Karr 2008; Wang 2009). Additionally, Darcy-Weisbach formula for flow resistance is taken into account.

The influence of the significant parameters on the character and level of vibrations is studied. The possibility of exciting sub-harmonic and chaotic oscillations at certain intervals of excitation frequency and flow velocity is presented.

A few results of such studies are available in the literature. Usually frequency response curves and the time histories

* Cracow University of Technology, Krakow, Poland; ac@mech.pk.edu.pl; jluczko@mech.pk.edu.pl 
are shown only for the suitably chosen values of the systems parameters (Gorman et al. 2000; Lee and Chung 2002; Lee and Park 2006; Panda and Karr 2008). In some papers bifurcation diagrams (one-parameter diagrams) to determine the character of vibrations (Modarres-Sadeghi et al. 2005; Wang 2009) are calculated. Only in a few papers the influence of two parameters (two-parameters diagrams) on instability regions is studied. In this case linear systems are usually investigated. For example, Kadoli and Ganesan (2004) analyze the effect of tempera-ture of fluid on the instability regions in the plane: flow velocity - frequency of pulsation by using Floquet-Liapunov theory. Jin and Song (2005) introduce a non-linear model of the vertical pipe and determine the regions of parametric resonance in the plane: frequency - amplitude of pulsation.

In the present paper an effective algorithm based on the Galerkin method and Floquet theory, allowing for qualitative research of the system is proposed. Influence of velocity, frequency of pulsation and pressure and the flow resistance is investigated for the two types of pipes (rigid and flexible).

\section{THE MODEL OF THE SYSTEM}

The system under consideration consists of a horizontal pipe of length $l$, cross-sectional area $A_{p}$, mass per unit length $m_{p}$, and flexural rigidity $E I_{p}$, conveying a viscous incompressible fluid of mass per unit length $m_{f}$ with axial velocity $U_{f}$ and pressure $p$, which varies with time. The pipe is simply supported at both ends (Fig. 1). The pipe is considered to be slender, its lateral deflection small compared to the length of the pipe, so that the Euler-Bernoulli theory is applicable for describing the pipe dynamic bending. For the description of transverse and longitudinal vibrations of the pipe coordinates $w(x, t)$ and $u(x, t)$ are introduced. The relative motion of fluid determines the coordinate $s(t)$. It is assumed that the flow velocity $U_{f}=\dot{s}(t)$ is independent of the variable $x$ and is constant throughout the section.

The system of forces acting on the fluid element and the pipe element is shown in Figure 2.

In the model transverse forces $Q$, axial forces $T$, pressure forces $p A$ (where $A$ - internal cross-sectional area) and normal $n$ and tangential $\tau$ components of internal forces were taken into account.

In order to determine the motion of fluid element and pipe element the system of four partial differential equations, which result from balance of inertial forces and forces acting on the examined elements should be analyzed. Taking into account the influence of axial forces, Voigt-Kelvin model for internal damping and the assumption of small vibrations, after elimination of internal forces $n$ and $\tau$ the transverse motion of pipe with fluid can be described by equation (Païdoussis 1987, 1998):

$$
\begin{aligned}
& m \frac{\partial^{2} w}{\partial t^{2}}+m_{f}\left[\frac{\partial^{2} w}{\partial x^{2}} U_{f}^{2}+2 \frac{\partial^{2} w}{\partial x \partial t} U_{f}+\frac{\partial w}{\partial x} \frac{\partial U_{f}}{\partial t}\right]+ \\
& +\frac{\partial}{\partial x}\left[(p A-T) \frac{\partial w}{\partial x}\right]+E I_{p}\left[\frac{\partial^{4} w}{\partial x^{4}}+\alpha \frac{\partial^{5} w}{\partial x^{4} \partial t}\right]=0
\end{aligned}
$$

where $\alpha$ is a coefficient of internal damping and $m=m_{p}+m_{f}$.

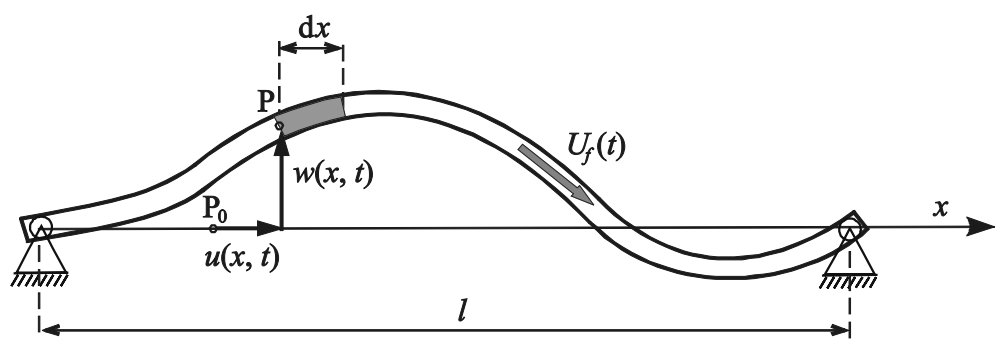

Fig. 1. Model of the system

a)

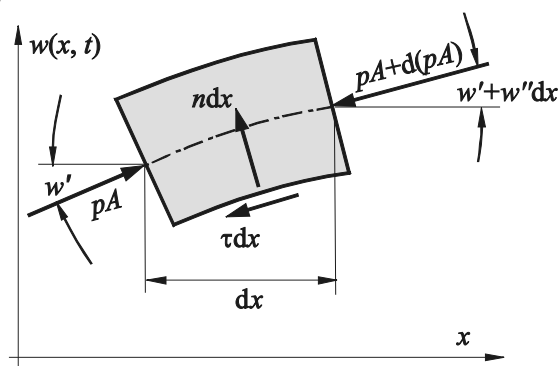

b)

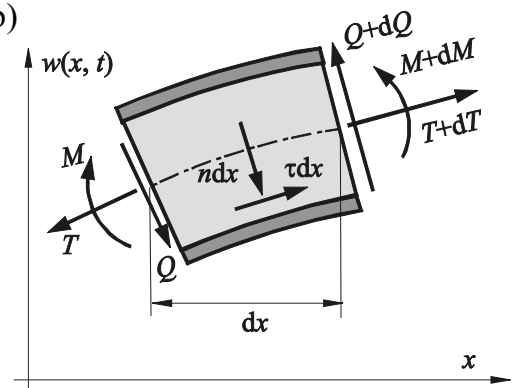

Fig. 2. Indication of forces: a) fluid element; b) pipe element 
In order to determine the component $(p A-T)$ the axial forces acting on the element pipe with fluid should be analyzed. By neglecting the effect of axial vibration the simplified form of equation is obtained (Paidoussis 1998):

$$
\frac{\partial(p A-T)}{\partial x}=-m_{f} \frac{\partial U_{f}}{\partial t}
$$

from which, after the integration from any $x$ to $l$, a relationship appears:

$$
p A-T=p(l, t) A-T(l, t)+m_{f} \frac{\partial U_{f}}{\partial t}(l-x)
$$

showing that the pressure decreases linearly with the variable $x$. Assuming that the pressure at the output is constant $p(l, t)=p_{0}$, the unknown quantity in expression (3) is the only value $T(l, t)$ of the axial force on the right end of the pipe. Taking into account the geometrical non-linearities, the axial force can be determined from the formula:

$$
\begin{aligned}
& T(x, t)=T_{0}+ \\
& +E A_{p}\left[\frac{\partial u}{\partial x}+\frac{1}{2}\left(\frac{\partial w}{\partial x}\right)^{2}+\alpha\left(\frac{\partial^{2} u}{\partial x \partial t}+\frac{\partial w}{\partial x} \frac{\partial^{2} w}{\partial x \partial t}\right)\right]
\end{aligned}
$$

where $E A_{p}$ represents axial stiffness of the pipe and $T_{0}$ is a static component of the axial force. On the other hand, for the tangential forces in the pipe-fluid system Darcy-Weisbach formula (Kuiper et al. 2007; Modarres-Sadeghi et al. 2005) can be used:

$$
\tau=-\frac{\partial T}{\partial x}=m_{f} \frac{\lambda}{2 d} U_{f}^{2}
$$

where $d$ is internal diameter of pipe and $\lambda$ is dimensionless friction factor depending on the Reynolds number. After the relationship (5) is integrated in similar limits as above, the axial force can be given by the following formula:

$$
T(x, t)=T(l, t)+m_{f} \frac{\lambda}{2 d} U_{f}^{2}(l-x)
$$

Comparing the value of axial force (4) averaged over the length of pipe:

$$
\bar{T}(t)=T_{0}+\frac{E A_{p}}{l}\left[1+\alpha \frac{\partial}{\partial t}\right] \int_{0}^{l}\left[\frac{\partial u}{\partial x}+\frac{1}{2}\left(\frac{\partial w}{\partial x}\right)^{2}\right] d x
$$

with the corresponding mean value calculated from the equation (6):

$$
\bar{T}(t)=T(l, t)+m_{f} \frac{\lambda l}{4 d} U_{f}^{2}
$$

the value of axial force can be determined at the right end of the pipe. Because of pinned-pinned pipe the additional constrains $u(0, t)=u(l, t)=0$ finally allow the value $T(l, t)$ to be calculated from the formula:

$$
\begin{aligned}
& T(l, t)=T_{0}-m_{f} \frac{\lambda l}{4 d} U_{f}^{2}+ \\
& +\frac{E A_{p}}{l} \int_{0}^{l}\left[\frac{1}{2}\left(\frac{\partial w}{\partial x}\right)^{2}+\alpha \frac{\partial w}{\partial x} \frac{\partial^{2} w}{\partial x \partial t}\right] d x
\end{aligned}
$$

After substituting the formulae (3) and (9) into equation (1) it takes the final form:

$$
\begin{aligned}
& m \frac{\partial^{2} w}{\partial t^{2}}+m_{f}\left[\frac{\partial^{2} w}{\partial x^{2}} U_{f}^{2}+2 \frac{\partial^{2} w}{\partial x \partial t} U_{f}\right]+ \\
& +\left(p_{0} A-T_{0}\right) \frac{\partial^{2} w}{\partial x^{2}}+E I_{p}\left[\frac{\partial^{4} w}{\partial x^{4}}+\alpha \frac{\partial^{5} w}{\partial x^{4} \partial t}\right]+ \\
& +\left[m_{f} \frac{\lambda l}{4 d} U_{f}^{2}+m_{f} \frac{\partial U_{f}}{\partial t}(l-x)-\frac{E A_{p}}{l} \times\right. \\
& \left.\times \int_{0}^{l}\left[\frac{1}{2}\left(\frac{\partial w}{\partial x}\right)^{2}+\alpha \frac{\partial w}{\partial x} \frac{\partial^{2} w}{\partial x \partial t}\right] d x\right] \frac{\partial^{2} w}{\partial x^{2}}=0
\end{aligned}
$$

For the laminar flow $(\operatorname{Re}<2100-2300)$ friction factor $\lambda$ is calculated from formula:

$$
\lambda=\frac{75}{\operatorname{Re}}
$$

In case of turbulent flow $(2300<\operatorname{Re}<50000)$ is used the Blasius's formula for hydraulically smooth pipes:

$$
\lambda=\frac{0.3164}{\sqrt[4]{\operatorname{Re}}}
$$

In the papers concerning similar problems dimensionless variables are used. All displacements are divided by the length of the pipe $l$ :

$$
z(\xi, \tau)=w(x, t) / l
$$

where:

$$
\xi=x / l
$$

Dimensionless time is defined using relation: $\tau=\omega_{0} t$, where:

$$
\omega_{0}=\sqrt{\frac{E I_{p}}{m l^{4}}}
$$


Equation (10) in dimensionless variables takes the form:

$$
\begin{aligned}
& \ddot{z}+2 \beta U \dot{z}^{\prime}+ \\
& +\left[(1+\gamma) U^{2}+\sigma-q+\beta \dot{U}(1-\xi)-\frac{1}{\rho^{2}} \int_{0}^{1}\left(\frac{1}{2} z^{2}+\zeta z^{\prime} \dot{z}^{\prime}\right) d \xi\right] \times \\
& \times z^{\prime \prime}+z^{I V}+\zeta \dot{z}^{I V}=0
\end{aligned}
$$

where differentiation with respect to the variable $\tau$ is marked by dot and differentiation with respect to the variable $\xi$ is marked by prim. The parameters appearing in equation (16) are defined by the formulae:

$$
\begin{aligned}
& \beta=\sqrt{\frac{m_{f}}{m}} \quad U=\frac{\beta U_{f}}{\omega_{0} l} \quad \zeta=\alpha \omega_{0} \quad \rho=\sqrt{\frac{I_{p}}{A_{p} l^{2}}} \\
& q=\frac{T_{0} l^{2}}{E I_{p}} \quad \sigma=\frac{p_{0} A l^{2}}{E I_{p}} \quad \gamma=\frac{\lambda(\mathrm{Re}) l}{4 d} \quad v=\frac{\nu_{f}}{\omega_{0} l^{2}}
\end{aligned}
$$

The value of coefficient $\gamma$ depends by formulae (11) and (12) on the Reynolds number $\operatorname{Re}=U_{f} d / \nu_{f}=U d / v \beta l$, which depends on the dimensionless parameters $v, U$ and $\beta$.

\section{THE METHOD OF ANALYSIS}

As a first step towards solving the nonlinear partial differential equation (16), it is transformed into a set of second-order ordinary differential equations using Galerkin's technique (Lee and Chung 2002; Wang 2009) with the beam eigenfunctions. For simply supported pipe the approximate solution can be assumed in the following form:

$$
z(\xi, \tau)=\sum_{k=1}^{N} z_{k}(\tau) \sin k \pi \xi
$$

Due to the influence of gyroscopic effects, in the numerical calculation an even number of forms $(N=4)$ is included. In this case, after applying the Galerkin method and taking into account the conditions of orthogonality of trigonometric functions, set of four second-order ordinary differential equations is obtained in the form: where:

$$
f=q-\sigma-(1+\gamma) U^{2}-\frac{1}{2} \beta \dot{U}+f_{N L}
$$

and:

$$
\begin{aligned}
& f_{N L}=\frac{1}{4 \rho^{2}}\left[z_{1}^{2}+4 z_{2}^{2}+9 z_{3}^{2}+16 z_{4}^{2}+\right. \\
& \left.+2 \zeta\left(z_{1} \dot{z}_{1}+4 z_{2} \dot{z}_{2}+9 z_{3} \dot{z}_{3}+16 z_{4} \dot{z}_{4}\right)\right]
\end{aligned}
$$

Equations (19) include the influence of gyroscopic effects (terms with parameter $\beta U$ ), internal damping (parameter $\zeta$ ) and geometric non-linearities (term $f_{N L}$ ). These are nonlinear parametrical equations due to the dependence of the dimensionless flow velocity on the time. The velocity of flow is assumed to be harmonically varying:

$$
U=U_{0}\left(1+A_{U} \sin \omega \tau\right)
$$

where $U_{0}$ is the mean velocity and $A_{U}$ is amplitude of pulsation and $\omega$ is excitation frequency.

The set of nonlinear equations (19) can be solved by using the methods of numerical integration, such as the Runge-Kutta methods. After using the relation (18) the displacements and velocities at any point of the pipe can also be determined.

Estimation of the regions of parametric resonance in the plane of the parameters is associated with multiple solving the equations (19) for different values of this parameters. This fact requires a relatively long time of calculations.

In order to estimate the range of parametric resonance the linear system (equations (19) for $f_{N L}=0$ ) can be analyzed. In this case a very effective way to study the stability is the method based on the Floquet theory. In order to investigate the stability of solutions, the eigenvalues of the monodromy matrix (Floquet multipliers) are used. The main advantage of this method is a relatively short time of numerical calculations due to the fact, that to determine the monodromy matrix the requirement is integration of differential equations (19) in one period of excitation only.

$$
\begin{aligned}
& \ddot{z}_{1}+\zeta \pi^{4} \dot{z}_{1}+\pi^{2}\left(\pi^{2}+f\right) z_{1}-\beta U\left[\frac{16}{3} \dot{z}_{2}+\frac{32}{15} \dot{z}_{4}\right]-\beta \dot{U}\left[\frac{64}{9} z_{2}+\frac{512}{225} z_{4}\right]=0 \\
& \ddot{z}_{2}+16 \zeta \pi^{4} \dot{z}_{2}+4 \pi^{2}\left(4 \pi^{2}+f\right) z_{2}+\beta U\left[\frac{16}{3} \dot{z}_{1}-\frac{48}{5} \dot{z}_{3}\right]-\beta \dot{U}\left[\frac{16}{9} z_{1}+\frac{432}{25} z_{3}\right]=0 \\
& \ddot{z}_{3}+81 \zeta \pi^{4} \dot{z}_{3}+9 \pi^{2}\left(9 \pi^{2}+f\right) z_{3}+\beta U\left[\frac{48}{5} \dot{z}_{2}-\frac{96}{7} \dot{z}_{4}\right]-\beta \dot{U}\left[\frac{192}{25} z_{2}-\frac{1536}{49} z_{4}\right]=0 \\
& \ddot{z}_{4}+256 \zeta \pi^{4} \dot{z}_{4}+16 \pi^{2}\left(16 \pi^{2}+f\right) z_{4}+\beta U\left[\frac{32}{15} \dot{z}_{1}+\frac{96}{7} \dot{z}_{3}\right]-\beta \dot{U}\left[\frac{32}{225} z_{1}-\frac{864}{49} z_{3}\right]=0
\end{aligned}
$$




\section{NUMERICAL EXAMPLES}

The numerical calculations were performed for two types of hydraulic line: steel pipe (Young's modulus $E=2.1 \times 10^{11} \mathrm{~Pa}$, mass per unit length $m_{p}=0.222 \mathrm{~kg} / \mathrm{m}$ ) with outer diameter $10 \mathrm{~mm}$ and wall thickness $1 \mathrm{~mm}$ and hydraulic rubber hose $\left(E=3 \times 10^{8} \mathrm{~Pa}, m_{p}=0.25 \mathrm{~kg} / \mathrm{m}\right)$ with outer diameter $15.4 \mathrm{~mm}$ and wall thickness $3.7 \mathrm{~mm}$. Both of them have a length of $l=1 \mathrm{~m}$. Mass of oil per unit length is $m_{f}=0.0503 \mathrm{~kg} / \mathrm{m}$. The influence of the constant component of axial force $(q=0)$ was omitted. This data was used to calculate ranges of variation of dimensionless parameters (seen in Table 1).

Table 1

Values of dimensionless parameters of investigated hydraulic lines

\begin{tabular}{|l|c|c|}
\hline \multicolumn{1}{|c|}{ Parameter } & Steel pipe & Rubber hose \\
\hline Pulsation frequency $\omega$ & $1-30$ & $1-30$ \\
\hline Flow velocity $U_{0}$ & $0-1.5 \pi$ & $0-1.5 \pi$ \\
\hline Coefficient $\beta$ & 0.43 & 0.41 \\
\hline Damping coefficient $\zeta$ & 0.002 & 0.02 \\
\hline Radius of gyration $\rho$ & $3.2 \times 10^{-3}$ & $4.4 \times 10^{-3}$ \\
\hline Pressure $\sigma$ & $0-10$ & $0-10$ \\
\hline Kinematics viscosity $\nu$ & $3 \times 10^{-6}-15 \times 10^{-6}$ & $3 \times 10^{-5}-15 \times 10^{-5}$ \\
\hline
\end{tabular}

In the tested system the flow velocity is harmonically varying according to the relation (22). The influence of the parameters characterizing the excitation, such as mean flow velocity $U_{0}$, pulsation amplitude $A_{U}$ and frequency $\omega$ as well as the parameters of the hydraulic system such as pressure $\sigma$ at the end of the line and kinematic viscosity $v$, was determined.

Figure 3 illustrates the effect of the parameters $\tilde{U}_{0}$ and $\tilde{\omega}$ on the rms value of the vibration velocity (in one-fourth the length of the pipe). The figure shows boundaries of unstable regions determined from the condition, that the value of the maximum Floquet multiplier is greater than unity. In addition, the graphs the curves defining the relationship between the frequency of excitation and the natural frequency, for which in theory should occurs the parametric resonance are also shown.

Vibrations induced by fluid flow occur mainly for the velocity greater than the critical velocity. Below the critical velocity the vibration are generated only in the ranges of parametric resonance. This phenomenon is more visible in the case of the steel pipe. In Figure 3d-f we can see clearly the first three areas of the parametric resonance. The increase of viscosity (flow resistance) shifts the range of excitation of vibrations to the lower flow rate. For the flexible hose for viscosity equal $v=3 \cdot 10^{-4}$ (Fig. 3c) vibrations occur in the whole range of flow rates.

Figures 4 and 5 shows the influence of the parameters $\tilde{U}_{0}$ and $\tilde{\sigma}$ on the rms value of the vibration velocity. The solid line shows boundaries of unstable regions. The dashed line shows the relationship between the parameters $\tilde{U}_{0}$ and $\tilde{\sigma}$ for which relationship $\tilde{\omega}=2\left(\omega=2 \omega_{n 0}\right)$ occurs, that is a condition for principal parametric resonance. In the graph time histories and spectra of vibration velocity $V_{z}=\dot{z}(1 / 4, \tau)$ for selected values of the parameters $\tilde{U}_{0}$ and $\tilde{\sigma}$ are shown.
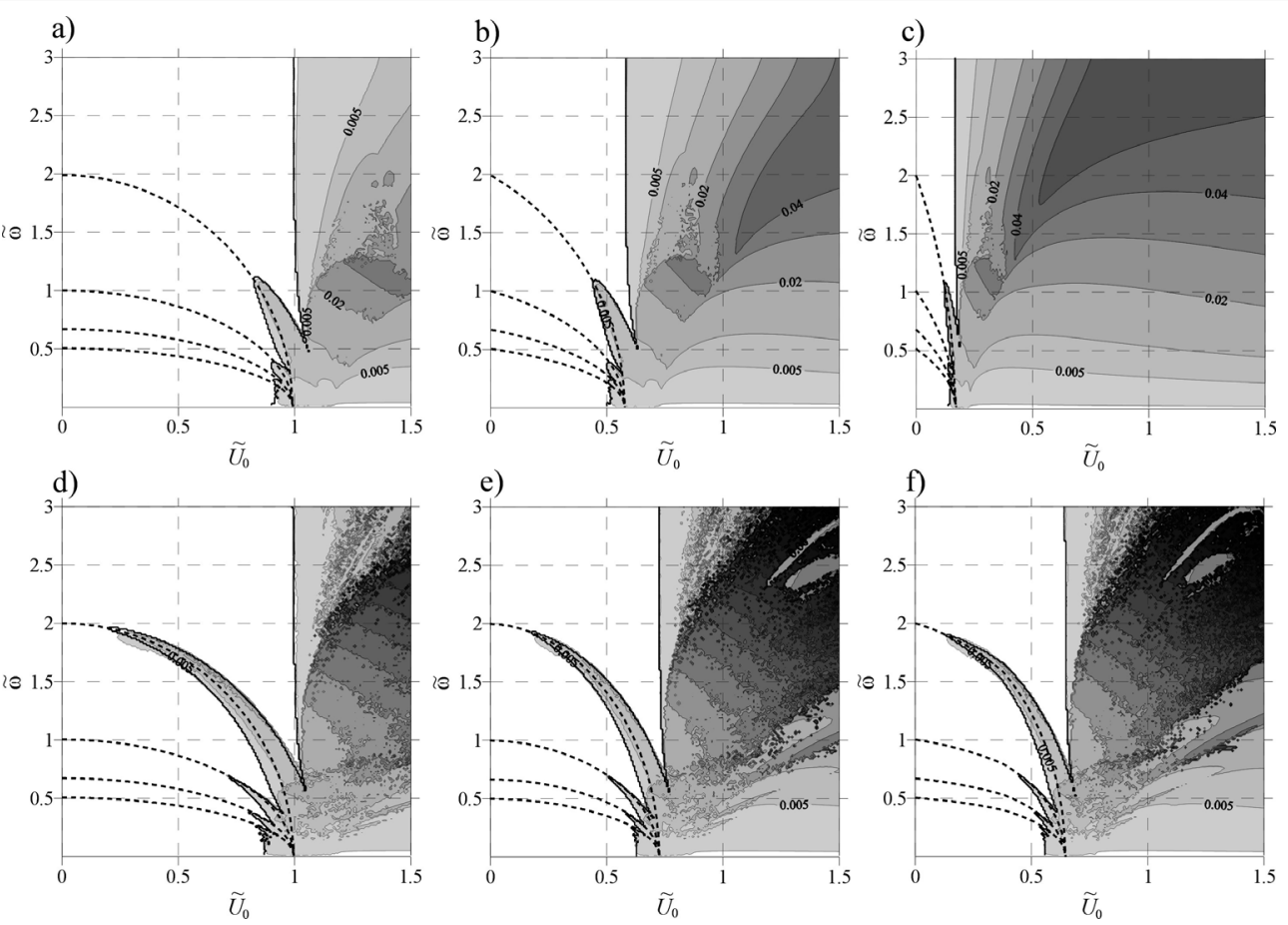

Fig. 3. The effect of the parameters $\tilde{U}_{0}$ and $\tilde{\omega}$ on the rms value of the vibration velocity $\left(\tilde{\sigma}=0, A_{U}=0.15\right)$ for flexible hose: a) $v=0$; b) $v=3 \times 10^{-5}$; c) $v=3 \times 10^{-4}$ and for steel pipe: d) $v=0$; e) $v=3 \times 10^{-6}$; f) $v=3 \times 10^{-5}$ 


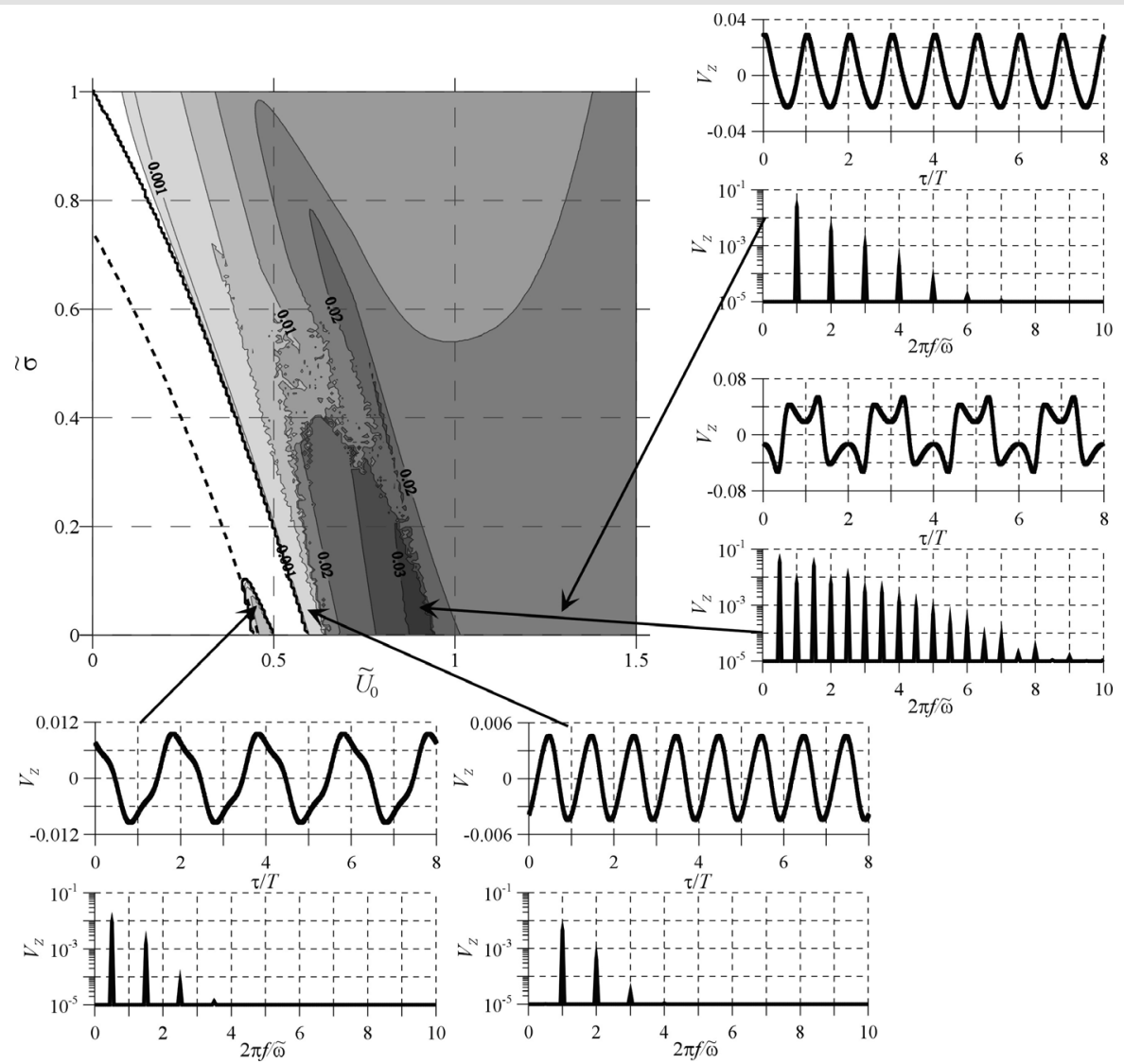

Fig. 4. The influence of the parameters $\tilde{U}_{0}$ and $\tilde{\sigma}$ on the rms value of the vibration velocity of the rubber hose at the lenght $\xi=1 / 4$ for $\tilde{\omega}=1, A_{U}=0.15, v=3 \times 10^{-6}$

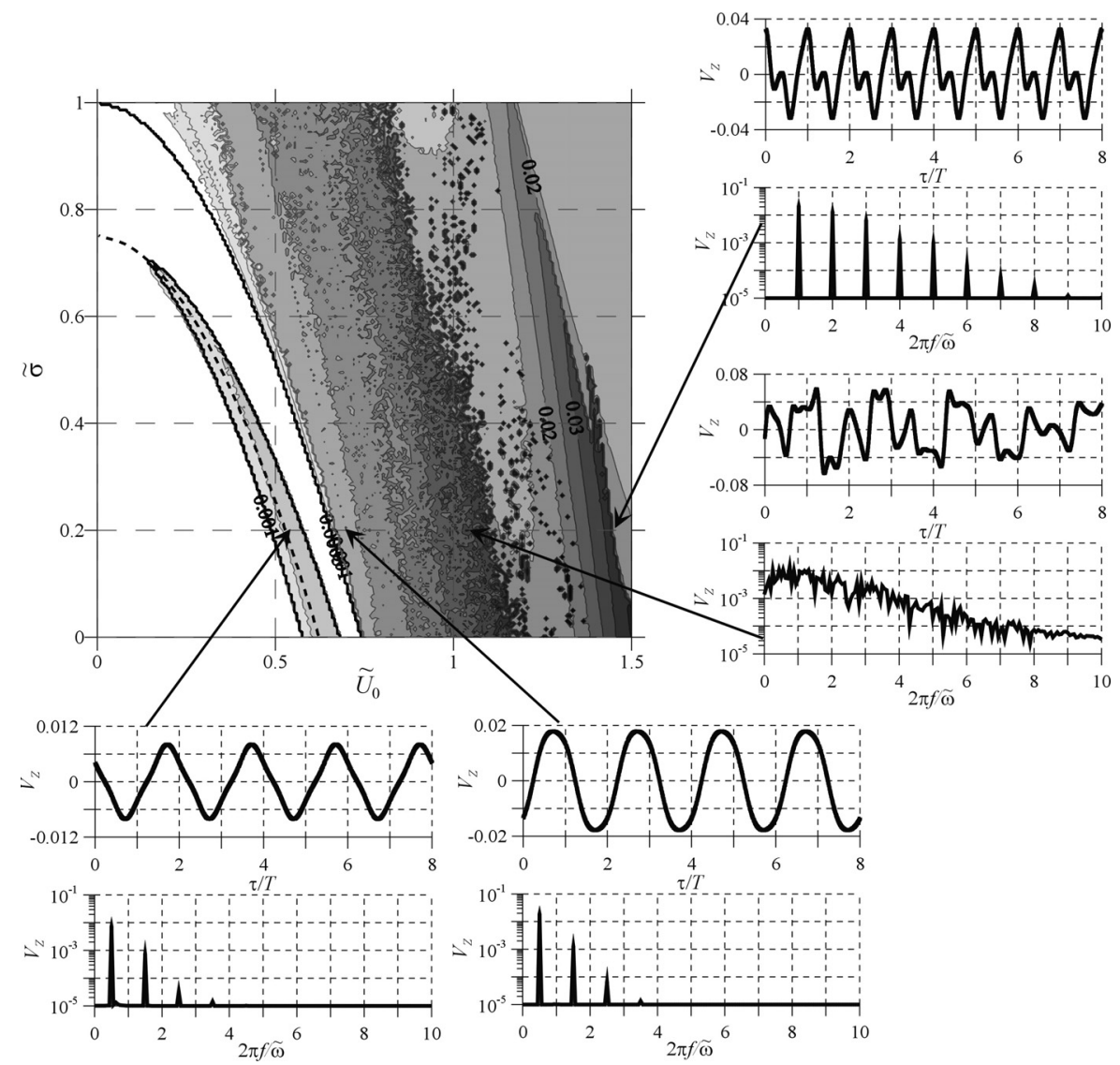

Fig. 5. The influence of the parameters $\tilde{U}_{0}$ and $\tilde{\sigma}$ on the rms value of the vibration velocity of the steel pipe at the length $\xi=1 / 4$ for $\tilde{\omega}=1, A_{U}=0.15, v=3 \times 10^{-6}$ 
By analyzing the results, it can be seen that the increase of pressure causes the decrease of flow velocity at which the vibration of the pipe are induced. The vibrations are generated in a relatively narrow region of parametric resonance, which was calculated based on the analysis of linear system. The observation of the time histories and the spectra of vibrations for the sub-critical velocity range confirms the phenomenon of parametric resonance in the system. The frequency of the pipe is equal to half of the excitation frequency. The vibration signal is polyharmonic. The spectrum consists only the odd harmonics.

The parametric resonance is more visible in the case of the steel pipe (Fig. 5). In the range of the velocity a few percent higher then critical velocity, the nature of vibrations depends on the type of hydraulic line. For the steel pipe period of vibration is twice as high as period of excitation (a typical feature of parametric oscillation), in the case of the flexible hose (Fig. 4) the frequency of oscillation is equal to the frequency of flow pulsation. For the steel pipe in the area of supercritical flow velocity, can be seen two regions of increased levels of vibrations. In the first region the vibrations are non-periodic (chaotic), in the second region the vibrations are periodic (with a frequency of extortion). In the case of the rubber hose with an increase of flow velocity is observed one maximum of vibration. In this area polyharmonic vibrations of frequency are equal to half of the excitation frequency. For higher flow velocity the hose vibrates with frequency of flow pulsation.

Figure 6 illustrates the influence of the velocity $\tilde{U}_{0}$ and pulsation amplitude $A_{U}$ on the rms value of the vibration velocity. On the plot are also shown the boundaries of unstable regions and vertical dashed line indicating the velocity value for which occurs relationship $\tilde{\omega}=2$. Increasing the amplitude of pulsation increases range of the velocity for which the parametric resonance can occur and also increases the level of vibration in the supercritical range.

In order to investigate the nature of the vibrations the stroboscopic bifurcation diagrams (for $A_{U}=0.1$ and $A_{U}=0.2$ ) were made by recording the value of vibration velocity $V_{z}$ at selected time instants (every excitation period).

The intervals on the diagram with a set of continuous lines are the regions of sub-harmonic oscillations of type 1:n ( $n T$ - periodic vibrations), where the number of lines provides information about the order. In other intervals the vibration are chaotic.

In order to confirm the nature of chaotic vibration Poincare maps (stroboscopic portraits) on the phase plane $\left(Z, V_{z}\right)$, where $Z=z(1 / 4, \tau)$, are made. Figure 7 shows the stroboscopic portraits for the flexible hose (Fig. 7a, b) and steel pipe (Fig. 7c, d). Fractal structure of these portraits confirms chaotic motion.

Figure 8 shows a bifurcation diagram illustrating the influence of the pulsation frequency on the type of vibrations. Four regions of chaotic vibrations separated by the second or fourth-order sub-harmonic vibration ranges are shown. The spectra of chaotic signals (for $\tilde{\omega}=1.0, \tilde{\omega}=1.8$ ) are broadband, while the spectra of periodic signals (for $\tilde{\omega}=0.4$, $\tilde{\omega}=1.4, \tilde{\omega}=2.4$ ) are a discrete.
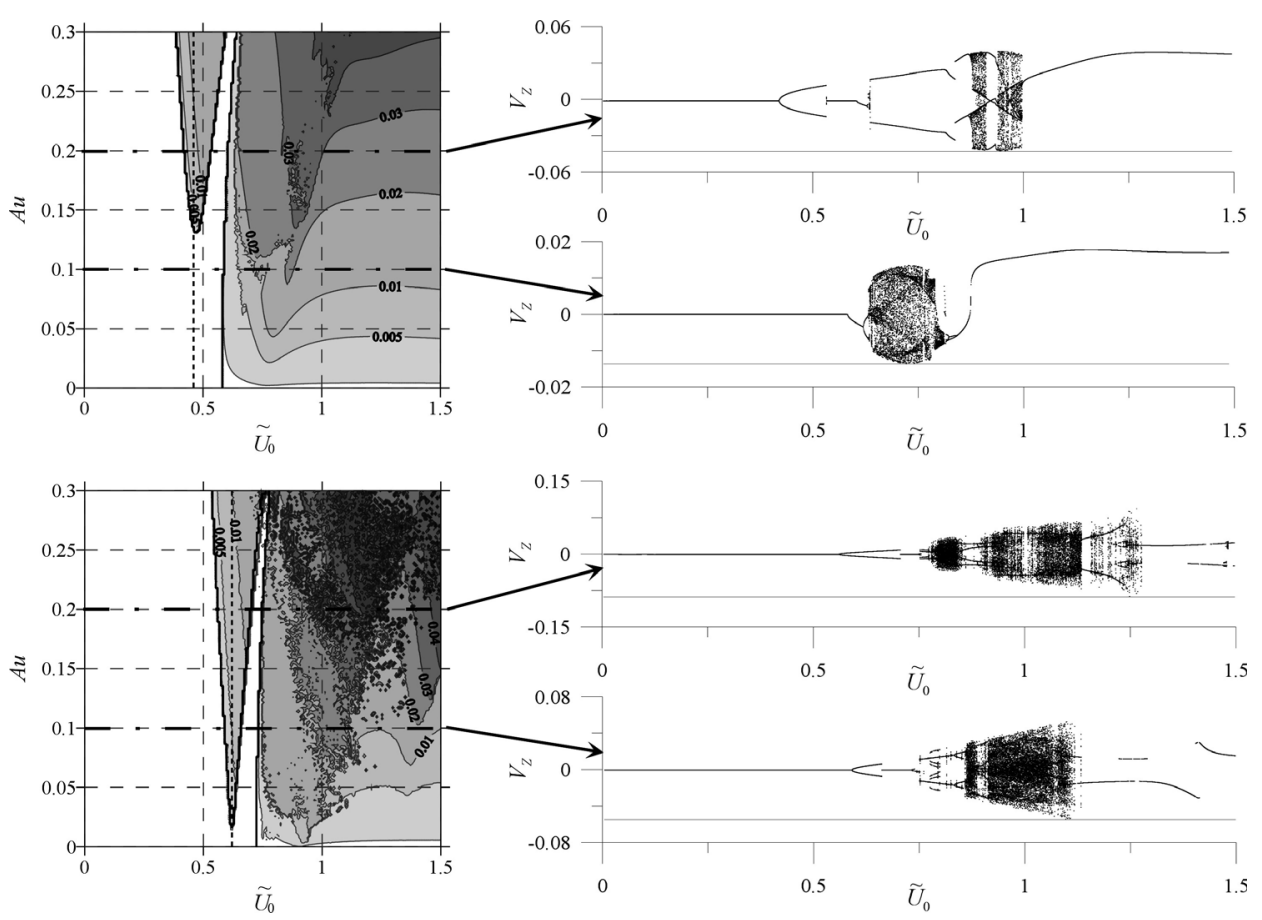

Fig. 6. The influence of the parameters $\tilde{U}_{0}$ and $A_{U}$ on the rms value of the vibration velocity for the rubber hose $\left(v=3 \times 10^{-5}\right)$ and the steel pipe $\left(v=3 \times 10^{-6}\right)$ at the length $\xi=1 / 4$ for $\tilde{\omega}=1$ 


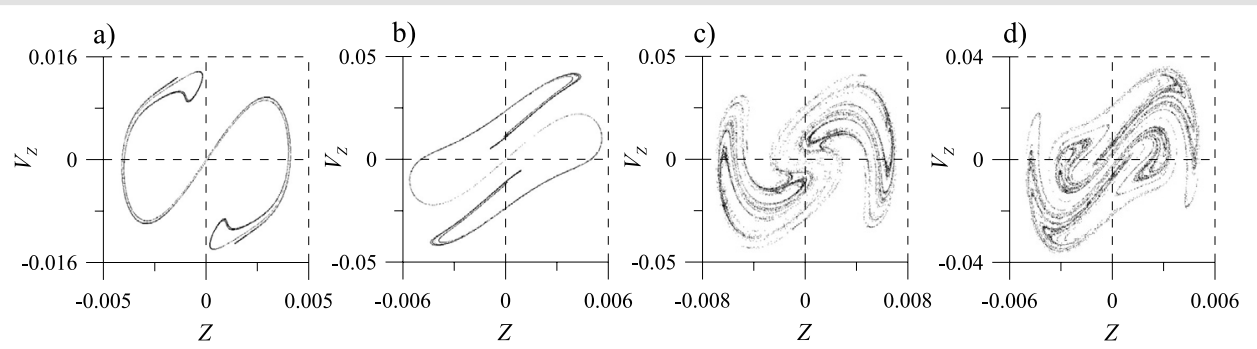

Fig. 7. The Poincare maps $(\tilde{\omega}=1)$ for the rubber hose: a) $A_{U}=0.1, \tilde{U}_{0}=0.75$; b) $A_{U}=0.2, \tilde{U}_{0}=0.9$ and the steel pipe: c) $A_{U}=0.1, \tilde{U}_{0}=0.8$; d) $A_{U}=0.2, \tilde{U}_{0}=1$

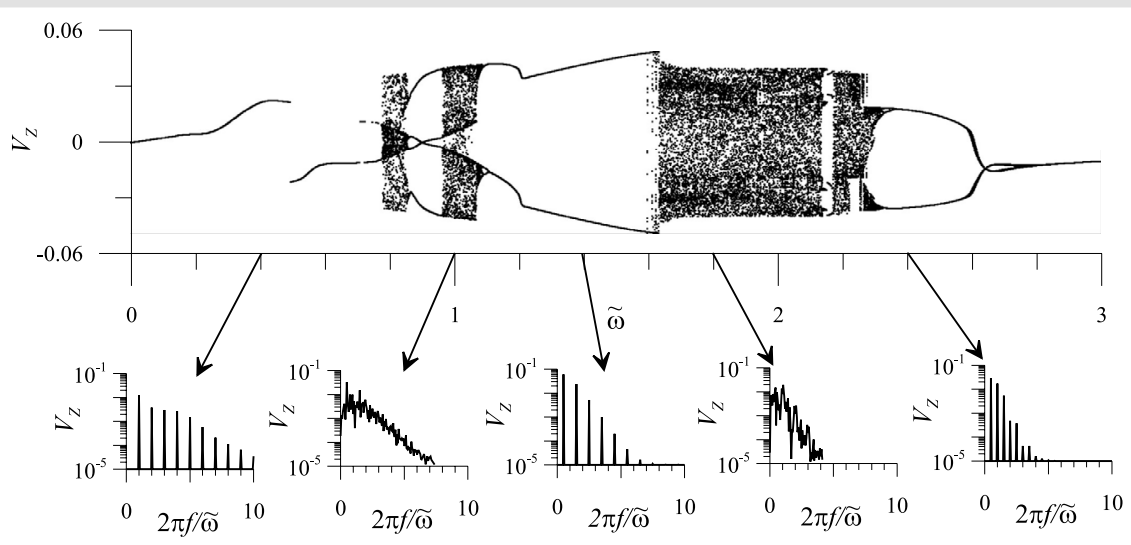

Fig. 8. The bifurcation diagram and the spectra of vibration velocity at selection points of diagram (the rubber hose: $A_{U}=0.2, \tilde{U}_{0}=0.9$ )

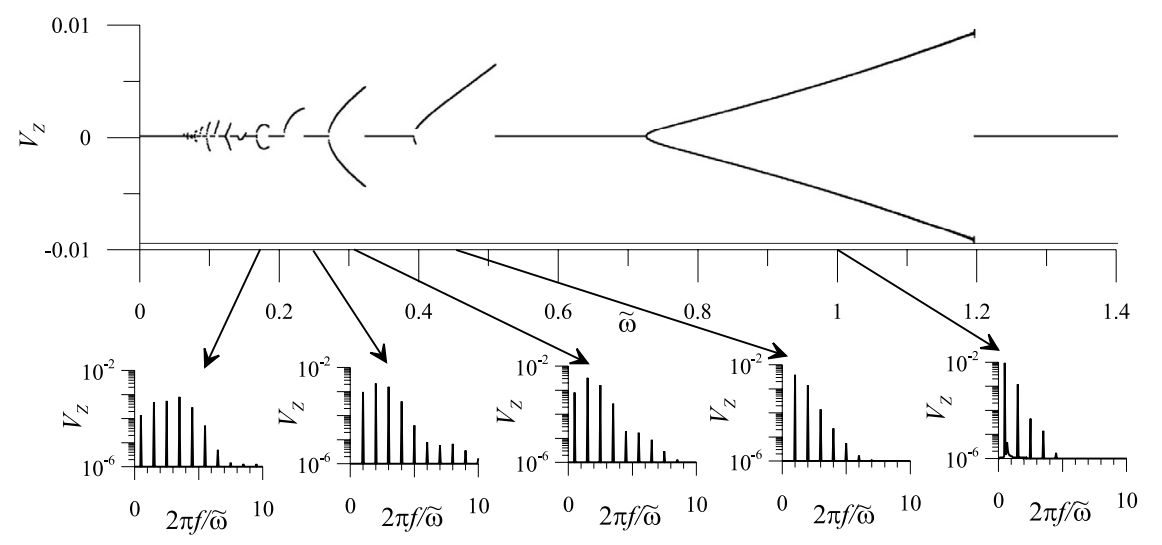

Fig. 9. The bifurcation diagram and the spectrum of vibration velocity at selection points of diagram (the steel pipe: $A_{U}=0.15, \tilde{U}_{0}=0.625$ )

An interesting case of diagram is shown in Figure 9. Analysis of this diagram confirms the phenomenon of parametric resonance. In the following areas of the parametric resonance vibration period is twice as high or equal to the excitation period.

\section{CONCLUSIONS}

From the analysis of the presented results the following conclusions can be drawn:

- The considered geometrically non-linear model allows to estimate the value of the vibration in the regions of parametric resonance and for flow velocity higher than the critical.
- Fluid flow in pipes with a velocity over the critical is the cause of vibration of large amplitude and in extreme cases may destroy the hydraulic system.

- Increasing of the pressure at the end of the pipe and an increase of flow resistance (viscosity) shift ranges of vibrations excitation (especially for the flexible hose) in the direction of lower velocity.

- For flow velocity lower than the critical, in some ranges of frequencies, parametric vibrations with frequency twice as high or equal to the frequency of pulsation are generated.

- The results of numerical simulations indicate the possibility of exciting the vibrations of a very different nature, including the sub-harmonic and chaotic vibration. 
- The results of numerical analysis can be the basis for selection of the hydraulic system in the planned experiment.

\section{References}

Bagchi K., Gupta S.K., Kushari A., Iyengar N.G.R., 2009, Experimental study of pressure fluctuations and flow perturbations in air flow through vibrating pipes, Journal of Sound and Vibration, 328, pp. 441-455.

Gorman D.G., Reese J.M., Zhang Y.L., 2000, Vibration of a flexible pipe conveying viscous pulsating fluid flow, Journal of Sound and Vibration, 230, 2, pp. 379-392.

Jin J.D., Song Z.Y., 2005, Parametric resonances of supported pipes conveying pulsating fluid, Journal of Fluids and Structures, 20, pp. 763-783.

Kadoli R., Ganesan N., 2004, Parametric resonance of a composite cylindrical shell containing pulsatile flow of hot fluid, Composite Structures, 65, pp. 391-404

Kuiper G.L., Metrikine A.V., Battjes J.A., 2007, A new time-domain drag description and its influence on the dynamic behaviour of a cantilever pipe conveying fluid, Journal of Fluids and Structures, 23 pp. 429-445.
Lee S. I., Chung J., 2002, New non-linear modelling for vibration analysis of a straight pipe conveying fluid, Journal of Sound and Vibration, 254, 2, pp. 313-325.

Lee U., Park J., 2006, Spectral element modelling and analysis of a pipeline conveying internal unsteady fluid, Journal of Fluids and Structures, 22, pp. 273-292.

Modarres-Sadeghi Y., Pad'doussis M.P., Semler C., 2005, A nonlinear model for an extensible slender flexible cylinder subjected to axial flow, Journal of Fluids and Structures, 21, pp. 609-627.

Païdoussis M.P., 1987, Flow-induced instability of cylindrical structures, Applied Mechanics, 40, 163-175.

Païdoussis, M.P., 1998, Fluid-Structure Interactions: Slender Structures and Axial Flow, vol. 1, Academic Press, London.

Panda L.N., Kar R.C., 2008, Nonlinear dynamics of a pipe conveying pulsating fluid with combination, principal parametric and internal resonances, Journal of Sound and Vibration, 309, pp. $375-406$

Wang L., 2009, A further study on the non-linear dynamics of simply supported pipes conveying pulsating fluid, International Journal of Non-Linear Mechanics, 44, pp. 115-121.

Zhang Y.L., Reese J.M., Gorman D.G., 2003, An experimental study of the effects of pulsating and steady internal fluid flow on an elastic tube subjected to external vibration, Journal of Sound and Vibration, 266, pp. 355-367. 